Check for updates

Cite this: Phys. Chem. Chem. Phys., 2020, 22, 15986

Received 1st April 2020,

Accepted 23rd June 2020

DOI: $10.1039 / \mathrm{d} 0 \mathrm{cp} 01771 \mathrm{j}$

rsc.li/pccp

\title{
Carbon dioxide and propane nucleation: the emergence of a nucleation barrier $\dagger$
}

\author{
Jan Krohn, (D) $\ddagger$ Martina Lippe, $\ddagger$ Chenxi Li (D) and Ruth Signorell (D) *
}

\begin{abstract}
We investigate homogeneous gas-phase nucleation of $\mathrm{CO}_{2}$ and $\mathrm{C}_{3} \mathrm{H}_{8}$ in the uniform postnozzle flow of Laval expansions in the temperature range of $31.2 \mathrm{~K}$ to $62.9 \mathrm{~K}$ and $32.0 \mathrm{~K}$ to $42.1 \mathrm{~K}$, respectively. Timedependent cluster size distributions are recorded with mass spectrometry after single-photon ionization with vacuum ultraviolet light. Net monomer-cluster forward rate constants and experimental nucleation rates $J$ are retrieved from the time-dependent cluster size distributions. The comparison of experimental enhancement factors derived from these net forward rates with calculated enhancement factors provides an indication for the transition from barrier-limited to barrierless nucleation. Our data suggest such a transition for $\mathrm{CO}_{2}$, but not for $\mathrm{C}_{3} \mathrm{H}_{8}$. The values of $\mathrm{J}$ lie in the range from $9 \times 10^{14} \mathrm{~cm}^{-3} \mathrm{~s}^{-1}$ to $6 \times 10^{15} \mathrm{~cm}^{-3} \mathrm{~s}^{-1}$. For $\mathrm{CO}_{2}$, the comparison of $\mathrm{J}$ with a modeled nucleation rate $J_{Q M}$ based on quantum chemical calculations of the free energy barrier also hints at a transition from barrierless condensation to barrier-limited nucleation. Furthermore, we address the influence of the carrier gas pressure on the nucleation rate.
\end{abstract}

\section{Introduction}

Gas phase nucleation, the first step in the phase transition from the gas phase to the liquid or solid phase, is an important step in technical processes, ${ }^{1}$ environmental processes ${ }^{2,3}$ and health science. ${ }^{4,5}$ Despite its high relevance, nucleation is still poorly understood at a fundamental level. Gas-phase nucleation occurs in a supersaturated parent phase when the supersaturation $S=\frac{p_{\text {cond }}}{p_{\mathrm{eq}}(T)}$ exceeds 1 ( $p_{\text {cond }}$ is the partial pressure of the condensable and $p_{\text {eq }}(T)$ is the equilibrium vapor pressure of the condensable at a given temperature). Nucleation processes are often characterized by the nucleation rate. Many different experimental studies have investigated nucleation rates with a variety of methods (see ref. 6-12 and references therein). Often, the number concentrations of particles of the new phase are retrieved from experimental data after nucleation and partial cluster growth have occurred, and classical nucleation theory (CNT) or variants of it are used to extract the nucleation rate. For some cases, it has been shown that the agreement between experimental nucleation rates and CNT predictions is very poor. ${ }^{7-9}$

Department of Chemistry and Applied Biosciences, Laboratory of Physical Chemistry, ETH Zürich, Vladimir-Prelog-Weg 2, CH-8093 Zürich, Switzerland. E-mail: rsignorell@ethz.ch; Fax: +41 44633 13 16; Tel: +41 446334621 $\dagger$ Electronic supplementary information (ESI) available. See DOI: 10.1039/ d0cp01771j

\# These authors contributed equally to this work.

$\S$ Current Address: School of Environmental Science and Engineering, Shanghai Jiaotong University, Shanghai 200240, China.
Even though the exact reasons for the large deviations between experiments and theory are unknown, the use of bulk properties to describe the molecular process by CNT is a well-known issue. In order to improve the theoretical predictions, empirical corrections $^{13}$ or microscopic corrections ${ }^{14-16}$ to CNT are used, but so far none of these approaches have been able to describe nucleation accurately over a wide range of experimental conditions and for different systems. Diemand et al. ${ }^{17}$ performed large scale molecular dynamics simulations for Ar nucleation, which enabled them to retrieve nucleation rates down to $\sim 1 \times 10^{17} \mathrm{~cm}^{-3} \mathrm{~s}^{-1}$. They demonstrated good agreement with the experiments previously performed by Wyslouzil and coworkers. ${ }^{9}$ Unfortunately, this computationally very expensive method has major limitations: simulations for more complicated molecular systems and for low nucleation rates are still too costly to be performed.

The rate-limiting step of nucleation is the formation of the critical cluster (nucleus), which corresponds to the cluster size where the Gibbs free energy reaches a maximum. The usual picture of gas-phase nucleation thus involves overcoming an energy barrier. However, in the limiting case of extremely high supersaturation, nucleation can become barrierless. ${ }^{18-21}$ Extremely high supersaturations can be achieved either by strongly increasing the concentration of the nucleating species or by substantially lowering the temperature. Alternatively, the energy barrier can also be modified by introducing another substance that provides an alternative nucleation pathway. ${ }^{18,19}$ The identification of the emergence (or disappearance) of an energy barrier as a function of thermodynamic variables is an 
important step towards a better molecular-level understanding of the nucleation process.

The transition from barrierless to barrier-limited nucleation can be identified in different ways. One possibility is the direct comparison between experimental nucleation rates and nucleation rates predicted for the gas kinetic limit. The main limitation of this approach arises from the usual approximation that the association rate is given by the collision rate. This only holds in the high pressure limit, i.e. for unit sticking probability. Another method is to utilize the first nucleation theorem to examine the size shift of the critical cluster for different supersaturations at constant temperature, ${ }^{22,23}$ which can be very challenging experimentally. The emergence (or disappearance) of an energy barrier is also reflected in the change of the relative magnitude of the cluster association and evaporation rates for varying conditions. Hence, the characterization of this change can also be used to probe the transition from barrierless to barrier-limited behavior. To the best of our knowledge, this approach has not yet been applied to experimental data, simply because the evaporation rates of clusters are usually not directly accessible in experiments.

In this work, we study homogeneous gas phase nucleation of weakly bound $\mathrm{CO}_{2}$ and $\mathrm{C}_{3} \mathrm{H}_{8}$ clusters at the molecular level in the uniform postnozzle flow of Laval expansions using soft single-photon ionization coupled with time-of-flight mass spectrometry. ${ }^{24-29}$ These experiments provide cluster size distributions as a function of the temperature, the concentration of the condensable gas and the nucleation time. Experimental nucleation rates are directly determined from these timedependent, cluster size-resolved data and compared with predicted nucleation rates. Our measurements are performed at high supersaturations $\left(S>10^{11}\right)$, where the region of barrierless nucleation or the transition to barrierless nucleation is reached. In our previous work on $\mathrm{H}_{2} \mathrm{O}$ nucleation, ${ }^{30}$ we developed a framework based on the general dynamic equation $(\mathrm{GDE})^{31}$ to calculate monomer-cluster association rate constants from experimental data under the assumption of negligible evaporation. The latter assumption is valid for $\mathrm{H}_{2} \mathrm{O}$ clusters at $47.5 \mathrm{~K}$ and $87.0 \mathrm{~K}$, and means that $\mathrm{H}_{2} \mathrm{O}$ condensation is barrierless under these conditions. Here, we apply the same framework to understand $\mathrm{CO}_{2}$ and $\mathrm{C}_{3} \mathrm{H}_{8}$ nucleation in a similar temperature range. Since $\mathrm{CO}_{2}$ and $\mathrm{C}_{3} \mathrm{H}_{8}$ clusters are more weakly bound than $\mathrm{H}_{2} \mathrm{O}$ clusters, it is not unlikely that the transition regime to barrier-limited nucleation is reached, in particular for $\mathrm{CO}_{2}$. Instead of extracting actual association rate constants as in the $\mathrm{H}_{2} \mathrm{O}$ nucleation study, we use the GDE framework to compare the relative magnitude of monomer-cluster association rate constants and cluster evaporation rate constants as we increase the system temperature from $\sim 30 \mathrm{~K}$ to $60 \mathrm{~K}$ for $\mathrm{CO}_{2}$. This allows us to identify the emergence of a nucleation barrier. In an attempt to partially overcome the deficiencies of CNT, we also compare our experimental results with density functional theory (DFT) calculations to gain information on the stability of the clusters.

\section{Experiment}

\subsection{Experimental setup}

The experimental setup has been described in detail in our previous publications, ${ }^{24-30}$ and is thus only briefly discussed here. Fig. 1 shows a simplified schematic of our experimental setup. Two pulsed feeding valves with an opening time of $6 \mu \mathrm{s}$ and a repetition rate of $20 \mathrm{~Hz}$ are used to supply the gas mixture to the stagnation volume with stagnation pressure $p_{0}$ and temperature $T_{0}$. We use mass flow controllers to regulate the flow of the carrier gas (Ar, PanGas 5.0), the internal standard gas $\left(\mathrm{CH}_{4}\right.$, Messer 5.5) and the condensable gas $\left(\mathrm{CO}_{2}\right.$, PanGas 4.5 or $\mathrm{C}_{3} \mathrm{H}_{8}$, Linde 3.5 ). The gas mixture is expanded through the Laval nozzle generating a uniform flow at the nozzle exit with flow temperature $T_{\mathrm{F}}$ and pressure $p_{\mathrm{F}}$. The uniform flow can be extended into the postnozzle region (100 $\mathrm{mm}$ in length) by matching the background pressure to $p_{\mathrm{F}}$. The Laval nozzle is mounted on a linear translation stage that allows us to change the axial distance $l$ between the nozzle exit and skimmer in steps as small as $1 \mathrm{~mm}$ with a positioning error of $25 \mu \mathrm{m}$ for $100 \mathrm{~mm}$ translation. A change in $l$ corresponds to a change in the nucleation time $t$. Depending on the properties of the expansion, the maximum time span that can be covered is $\sim 200 \mu \mathrm{s}$ with a temporal resolution of $\sim 2 \mu \mathrm{s}$. The Mach number $M$ and flow temperature $T_{\mathrm{F}}$ are determined from $p_{0}$ and from the impact pressures $p_{\mathrm{I}}$ using the Rayleigh-Pitot equation, which is valid under isentropic flow conditions and for ideal gas behavior (for more information see ref. 24-30).

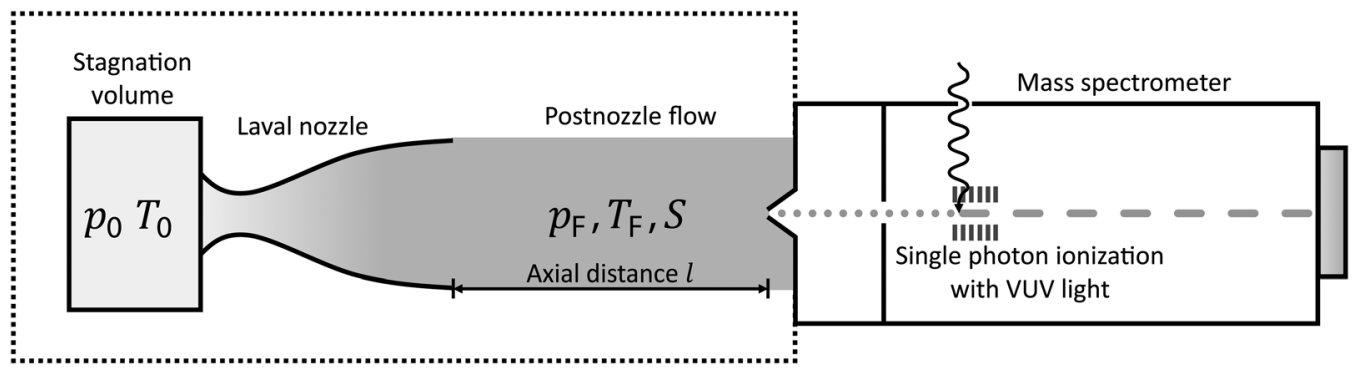

Fig. 1 Simplified schematic of the experimental setup with the Laval setup and a mass spectrometer. $T_{0}$ and $p_{0}$ are the stagnation temperature and pressure, respectively, and $T_{F}$ and $p_{F}$ are the flow temperature and pressure, respectively. $S$ is the supersaturation. The axial distance $l$ is the distance between the nozzle exit and skimmer. 
20 to 40 individual measurements of $p_{0}$ and $p_{\mathrm{I}}$ are typically recorded for a given axial distance. From these measurements, the axially averaged flow temperature $\overline{T_{\mathrm{F}}}$ and Mach number $\bar{M}$ with standard deviations $(1 \sigma)$ are determined. A skimmer ( $1 \mathrm{~mm}$ in diameter) is used to sample the core part of the postnozzle flow. We use single photons at $13.8 \mathrm{eV}(89.8 \mathrm{~nm})$ generated by a home-built table-top vacuum ultraviolet (VUV) laser to ionize the clusters. The VUV-photons are generated in a two-color-four-wave mixing process in a krypton expansion at $20 \mathrm{~Hz}$. Single-photon ionization has been proven to be a soft ionization technique also for weakly bound clusters. ${ }^{32-36}$ The cluster ions are then accelerated using a Wiley McLaren type mass spectrometer with acceleration voltages up to $30 \mathrm{kV}$ and finally detected using a microchannel plate (MCP) detector. The monomer has a $10^{3-4}$ times higher abundance than the clusters. Therefore, the monomer and the clusters have to be recorded in separate measurements using different experimental settings. ${ }^{28}$ A deflector electrode located in front of the MCP is used to deflect the monomer during the cluster measurements to avoid saturation effects on the MCP.

\subsection{Data processing}

The determination of the cluster number concentration from the recorded mass spectra is described in our previous publications. ${ }^{28,30}$ $\overline{T_{\mathrm{F}}}$ is varied by changing the Laval nozzle and by changing the compositions of the carrier gas (concentrations of $\mathrm{Ar}$ and $\mathrm{CH}_{4}$; see Table 1). $\mathrm{CH}_{4}$ gas also serves as an internal standard. The number concentration of $\mathrm{CH}_{4}, \mathrm{~N}^{\mathrm{CH}_{4}}$, is calculated from the ideal gas law. The number concentration of the clusters with $n$ monomer units, $N_{n}$, is determined by:

$$
N_{n}=\frac{I_{n}}{I_{\mathrm{CH}_{4}}} \frac{\sigma_{\mathrm{CH}_{4}}}{\sigma_{\text {cond }} \cdot n} \cdot N^{\mathrm{CH}_{4}}
$$

$I_{n}$ is the recorded ion signal of cluster $n, I_{\mathrm{CH}_{4}}$ is the ion signal of the internal standard and $\sigma_{\mathrm{CH}_{4}}$ and $\sigma_{\text {cond }}$ are the photoionization cross sections of $\mathrm{CH}_{4}$ and the condensable monomer, respectively. ${ }^{37-39}$ We assume that the photoionization cross section of cluster $n$ is $n \cdot \sigma_{\text {cond }}$, which is consistent with physical considerations. ${ }^{28}$ We can calculate $N_{1}$ either from eqn (1) or from the ideal gas law. The results typically differ by $10-30 \%$, which provides an estimate for the uncertainty. In this work, we use the ideal gas law. At the lowest temperature $\left(\overline{T_{\mathrm{F}}}=32.0 \pm 1.5 \mathrm{~K}\right), \mathrm{CH}_{4}$ forms co-clusters with $\mathrm{C}_{3} \mathrm{H}_{8}$. In this case, we use the $\mathrm{C}_{3} \mathrm{H}_{8}$ monomer itself as the internal standard for the determination of the cluster number concentrations. This is reasonable as monomer depletion due to cluster formation is negligible under our conditions. We estimate an overall experimental uncertainty of the cluster number concentrations of about a factor of five for all cluster sizes (see ref. 28 and 30).

At early nucleation times $t$, i.e. when monomer depletion and coagulation can be neglected, the total cluster number concentration summed over all $n>n_{\mathrm{c}}, N_{\text {cluster,tot }>n_{\mathrm{c}}}$, provides direct access to the experimental nucleation rate $J$ (see Fig. 5 in ref. 28 and Sections 4.4 and 4.5 in this work):

$$
J=\frac{\partial N_{\text {cluster,tot }>n_{\mathrm{c}}}(t)}{\partial t}
$$

The relative uncertainty between nucleation rates recorded under different experimental conditions is estimated to be a factor of two. This estimate includes uncertainties from the choice of $n_{\mathrm{c}}$, the integration of the ion signal and from the linear fit to $N_{\text {cluster,tot }>n_{c}}$. Note that the choice of $n_{\mathrm{c}}$ does not have a significant influence if it is varied between one and six. The absolute uncertainty of the experimental nucleation rates is estimated to be one order of magnitude (see ref. 28 and 30). This estimate includes uncertainties of the absolute number concentrations as well as the aforementioned uncertainties.

Evaporation of a few monomer units upon photoionization cannot be excluded. To estimate the maximum number of monomer units that could be evaporated, let us assume that all excess energy provided by the photons resides in the cluster

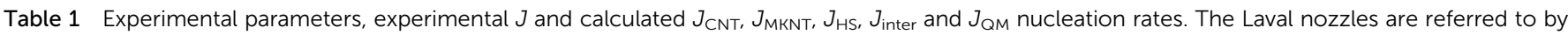

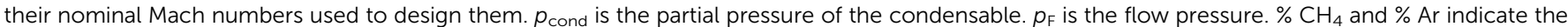

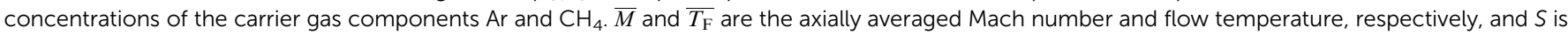

\begin{tabular}{|c|c|c|c|c|c|c|c|}
\hline & $50 \% \mathrm{CO}_{2}$ & $10 \% \mathrm{CO}_{2}$ & $3.3 \% \mathrm{CO}_{2}$ & $1.1 \% \mathrm{CO}_{2}$ & $0.12 \% \mathrm{CO}_{2}$ & $0.26 \% \mathrm{C}_{3} \mathrm{H}_{8}$ & $0.035 \% \mathrm{C}_{3} \mathrm{H}_{8}$ \\
\hline Symbol & $\star$ & $\nabla$ & P & $>$ & $\square$ & $\Delta$ & 1 \\
\hline Nozzle & Mach 5.2 & Mach 5.2 & Mach 5.2 & Mach 5 & Mach 6 & Mach 5 & Mach 6 \\
\hline$p_{\text {cond }} / \mathrm{Pa}$ & 13.25 & 2.65 & 0.88 & 0.37 & 0.04 & 0.086 & 0.012 \\
\hline$p_{\mathrm{F}} / \mathrm{Pa}$ & 26.5 & 26.5 & 26.5 & 33 & 35 & 33 & 35 \\
\hline$\% \mathrm{CH}_{4}$ & 7.7 & 23.1 & 15.4 & 1.7 & 1.5 & 0.87 & 0 \\
\hline$\% \mathrm{Ar}$ & 42.3 & 66.9 & 81.3 & 97.1 & 98.3 & 98.9 & 100 \\
\hline$\overline{T_{\mathrm{F}}} / \mathrm{K}$ & $62.9 \pm 1.1$ & $56.6 \pm 1.3$ & $49.3 \pm 1.3$ & $44.4 \pm 1.5$ & $31.2 \pm 1.3$ & $42.1 \pm 1.1$ & $32.0 \pm 1.5$ \\
\hline $\bar{M}$ & $3.83 \pm 0.06$ & $4.16 \pm 0.06$ & $4.65 \pm 0.07$ & $4.17 \pm 0.08$ & $4.89 \pm 0.11$ & $4.28 \pm 0.06$ & $4.96 \pm 0.11$ \\
\hline $\ln S$ & 26 & 30 & 38 & 45 & 78 & 44 & 66 \\
\hline$J / \mathrm{cm}^{-3} \mathrm{~s}^{-1}$ & $3.6 \times 10^{15}$ & $4.0 \times 10^{15}$ & $3.4 \times 10^{15}$ & $2.7 \times 10^{15}$ & $1.5 \times 10^{15}$ & $9.1 \times 10^{14}$ & $5.8 \times 10^{15}$ \\
\hline$J_{\mathrm{CNT}} / \mathrm{cm}^{-3} \mathrm{~s}^{-1}$ & $1.1 \times 10^{22}$ & $6.5 \times 10^{20}$ & $1.1 \times 10^{20}$ & $2.4 \times 10^{19}$ & $4.7 \times 10^{17}$ & $8.5 \times 10^{17}$ & $6.6 \times 10^{16}$ \\
\hline$J_{\mathrm{MKNT}} / \mathrm{cm}^{-3} \mathrm{~s}^{-1}$ & $5.9 \times 10^{3}$ & $6.8 \times 10^{-1}$ & $5.3 \times 10^{-3}$ & $1.2 \times 10^{-4}$ & $3.7 \times 10^{-8}$ & $2.4 \times 10^{-6}$ & $8.1 \times 10^{-10}$ \\
\hline$J_{\mathrm{HS}} / \mathrm{cm}^{-3} \mathrm{~s}^{-1}$ & $1.8 \times 10^{22}$ & $8.5 \times 10^{20}$ & $1.1 \times 10^{20}$ & $2.4 \times 10^{19}$ & $4.7 \times 10^{17}$ & $2.2 \times 10^{18}$ & $6.6 \times 10^{16}$ \\
\hline$J_{\text {inter }} / \mathrm{cm}^{-3} \mathrm{~s}^{-1}$ & $5.3 \times 10^{22}$ & $2.6 \times 10^{21}$ & $3.6 \times 10^{20}$ & $7.9 \times 10^{19}$ & $1.8 \times 10^{18}$ & $4.2 \times 10^{18}$ & $1.5 \times 10^{17}$ \\
\hline$J_{\mathrm{QM}} / \mathrm{cm}^{-3} \mathrm{~s}^{-1}$ & $5.4 \times 10^{17}$ & $2.6 \times 10^{16}$ & $3.5 \times 10^{16}$ & $3.3 \times 10^{16}$ & $4.7 \times 10^{16}$ & - & - \\
\hline
\end{tabular}
the supersaturation 
instead of being converted to the kinetic energy of the photoelectron. For this estimate, we use the vaporization enthalpy of $\mathrm{CO}_{2}$ and $\mathrm{C}_{3} \mathrm{H}_{8} \cdot{ }^{40-42}$ In the case of $\mathrm{CO}_{2}$, where ionization takes place very close to the lowest ionization energy, the simple estimate suggests that not even a single monomer unit would be evaporated. In the case of $\mathrm{C}_{3} \mathrm{H}_{8}$, for which the excess energy is higher, several monomer units could be evaporated. However, a large part of the excess energy is typically converted into the kinetic energy of the photoelectron and is thus not deposited into the cluster. Therefore, the true number of monomer units being evaporated from $\mathrm{C}_{3} \mathrm{H}_{8}$ clusters is likely less than a few molecules. We have tested that our kinetic model yields comparable results for the evaporation of one monomer unit upon ionization compared with no evaporation. Based on these estimates and results, we assume in the following that no monomer units are evaporated.

\section{Modeling}

\subsection{Fit of the net forward rate constant to experimental data}

The following describes the model used to extract the net forward rate constants from the experimental data. In eqn (3), we illustrate the kinetic pathways: $k_{1 j}$ is the true association rate constant, i.e. for the formation of cluster $j+1$ from cluster $j$. $N_{j+1}$ and $N_{j}$ are the respective number concentrations. $E_{j+1}$ is the evaporation rate constant of cluster $j+1$. As nucleation proceeds at constant temperature and pressure in our experiments, we assume that $k_{1 j}$ and $E_{j+1}$ are constant too.

$$
N_{1} \underset{E_{2}}{\stackrel{k_{11}}{k_{11, \text { net }}}} N_{2} \frac{k_{12}}{E_{3}} N_{3} \ldots N_{j} \overbrace{E_{j+1}}^{k_{12, \text { net }}} N_{j+1}
$$

$k_{1 j}$ and $E_{j+1}$ are not directly accessible in our experiment. We thus define a net forward rate constant $k_{1 j \text {,net }}$, which combines the contributions from association and evaporation as shown in eqn (3). This net rate constant is equal to the true association rate constant if evaporation is negligible. As discussed in detail in ref. 30 , we can extract the net forward rate constants $k_{1 j \text {,net }}$ using the following formula and further refine their values to fit the experimental cluster size distribution by visual inspection (see the ESI $\dagger$ for further information):

$$
k_{1 j, \text { net }}=\frac{\sum_{j}^{\infty} N_{j+1}\left(t_{\max }\right)-\sum_{j}^{\infty} N_{j+1}(0)}{\int_{0}^{t_{\max }} N_{1} N_{j} \mathrm{~d} t}
$$

$t_{\max }$ is the longest time accessible and corresponds to $l_{\max }$ (see Table 1).

\subsection{Molecular collision model and enhancement factor}

For simplicity, monomer-cluster association rate constants are often approximated by hard sphere collision rate constants $k_{1 j, \mathrm{HS}}$ that are given by: $:^{30,43}$

$$
k_{1 j, \mathrm{HS}}=\frac{1}{1+\delta_{1 j}}\left(\frac{3}{4 \pi}\right)^{1 / 6}\left(\frac{6 k_{\mathrm{B}} T}{\rho}\right)^{1 / 2} v_{1}^{1 / 6}\left(1+\frac{1}{j}\right)^{1 / 2}\left(1+j^{1 / 3}\right)^{2}
$$

with the Boltzmann constant $k_{\mathrm{B}}$, the bulk liquid density $\rho$, the monomer volume $v_{1}$, cluster size $j$ and the Kronecker delta $\delta_{1 j}$. Eqn (5) corresponds to using the geometrical cross section of the colliding entities. In this equation long-range intermolecular interactions, such as electrostatic and dispersion interactions, are not considered. These intermolecular interactions are generally not negligible, and typically result in enhanced collision rate constants $k_{1 j \text {,inter }}$ compared to $k_{1 j, \mathrm{HS}}{ }^{44-48}$ To predict $k_{1 j \text {,inter }}$, we use the following procedure. The $\mathrm{CO}_{2}$ cluster geometries are taken from the DFT calculations performed in our previous publication. ${ }^{29}$ The distance-dependent potential $V(R, \Omega)$ between a cluster of size $j$ and a monomer, at a relative orientation $\Omega$ to each other, is modeled with a force field (FF) $\operatorname{method}^{49}$ (see the ESI $\dagger$ for FF parameters and more details). The potential is averaged over the thermal distributions of relative orientations:

$$
V(R)=\frac{\sum_{\Omega} V(R, \Omega) \exp \left(-\frac{V(R, \Omega)}{k_{\mathrm{B}} T}\right)}{\sum_{\Omega} \exp \left(-\frac{V(R, \Omega)}{k_{\mathrm{B}} T}\right)}
$$

Using this potential, we determine the maximum impact parameter $b_{\max }$ for association as a function of the monomer's translational kinetic energy $E_{\mathrm{T}}$ (see the ESI $\dagger$ for further information). $k_{1 j \text {,inter }}$ is then given by: ${ }^{50}$

$$
k_{1 j \text {,inter }}=\frac{1}{1+\delta_{1 j}} \int_{0}^{\infty}\left(\frac{2 E_{\mathrm{T}}}{\mu}\right)^{1 / 2} \pi b_{1 j, \max }^{2}\left(E_{\mathrm{T}}\right) \chi\left(E_{\mathrm{T}}\right) \mathrm{d} E_{\mathrm{T}}
$$

where $\mu$ is the reduced mass of the system and $\chi\left(E_{\mathrm{T}}\right)$ is the Maxwell-Boltzmann distribution of the translational energy. The procedure for $\mathrm{C}_{3} \mathrm{H}_{8}$ is identical to the one outlined here for $\mathrm{CO}_{2}$, using a united-atom force field model. ${ }^{51}$ For $_{3} \mathrm{H}_{8}$, we only evaluate $k_{11 \text {,inter }}$ because of the many conformational isomers of $\mathrm{C}_{3} \mathrm{H}_{8}$ clusters. Already for the dimer, 23 stable configurations are reported. ${ }^{52}$

We define two enhancement factors to facilitate the interpretation of our data. The experimental enhancement factor $\eta_{\exp }$ is the ratio between the net forward rate constant and the hard sphere collision rate constant:

$$
\eta_{\exp }=\frac{k_{1 j, \text { net }}}{k_{1 j, \mathrm{HS}}}
$$

The calculated enhancement factor $\eta_{\text {calc }}$ is defined as follows:

$$
\eta_{\text {calc }}=\frac{k_{1 j, \text { inter }}}{k_{1 j, \mathrm{HS}}}
$$

The calculated collision rate constants $k_{1 j \text {,inter }}$ explicitly account for long-range intermolecular interactions, i.e. dispersion and quadrupole-quadrupole interactions. 


\subsection{Nucleation rates}

3.3.1 Collision-limited nucleation rates. If we assume that every collision between the condensable molecules leads to association, i.e. unit sticking probability, and that evaporation as well as coagulation are negligible, we can calculate the hard sphere nucleation rate $J_{\mathrm{HS}}$ with the rate constant $k_{11, \mathrm{HS}}$ from eqn (5) by:

$$
J_{\mathrm{HS}}=N_{1}^{2} k_{11, \mathrm{HS}}
$$

The formulae used for the density $\rho$ of $\mathrm{CO}_{2}$ and $\mathrm{C}_{3} \mathrm{H}_{8}$ can be found in the ESI. $\dagger J_{\mathrm{HS}}$ neglects long-range intermolecular interactions. We can take the latter into account, by utilizing

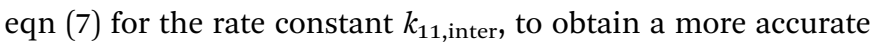
estimate of the upper limit of the nucleation rate:

$$
J_{\text {inter }}=N_{1}^{2} k_{11, \text { inter }}
$$

Note that some references (e.g. ref. 53) use an additional factor of $1 / 2$ in eqn (10) and (11). Here, this factor is incorporated into $k_{11, \mathrm{HS}}$ or $k_{11 \text {,inter }}$, respectively.

3.3.2 CNT. The steady-state or CNT nucleation rate is calculated as: ${ }^{43}$

$$
\begin{aligned}
J_{\mathrm{CNT}} & =N_{1}\left(\sum_{i=1}^{\infty} \frac{1}{N_{1} k_{1 i} \prod_{j=1}^{i-1} \frac{N_{1} k_{1 j}}{E_{j+1}}}\right)^{-1} \\
= & \frac{\frac{N_{1}^{2}}{k_{11}}+\frac{E_{2}}{S k_{12} N_{1} * k_{11}}+\frac{E_{2} E_{3}}{S^{2} k_{12} N_{1} k_{11} N_{1} k_{12}}+\ldots}{}
\end{aligned}
$$

with the evaporation rate constant $E_{j+1}$ and the association rate constant $k_{1 j}$, which usually are approximated by $k_{1 j, \mathrm{H} S}$ (see eqn (5)). Note that the quantities with an asterisk are evaluated at $S=1$, with $N_{1}{ }^{*}=\frac{N_{1}}{S}$. The equation can be expressed as a function of the Gibbs free energy of formation of cluster $j$ using detailed balance: ${ }^{54,55}$

$$
\prod_{i=1}^{j-1} \frac{E_{i+1}}{N_{1}{ }^{*} k_{1 i}}=\exp \left(\frac{\Delta G_{j}^{*}}{k_{\mathrm{B}} T}\right)
$$

where $\Delta G_{j}^{*}$ is the free energy of formation (standard Gibbs energy change for forming the cluster) for a saturated vapor with $S=1$ (see ref. 15, 16 and 56-59 for more information). In CNT, $\Delta G_{j}^{*}$ is calculated assuming the capillarity approximation ${ }^{57}$ from $\Delta G_{j}^{*}=\sigma s_{1}\left(j^{2 / 3}-1\right)$, with the surface tension of the bulk, $\sigma$, and the surface area of the monomer, $s_{1}$. If the critical cluster size is sufficiently large, the sum in eqn (12) can be replaced by a continuous integral. This leads to the commonly used formula in CNT (eqn (6) in ref. 28). However, in the present study the supersaturation is exceedingly high $\left(S>10^{11}\right)$, which means that only a few terms in eqn (12) contribute to the sum. We therefore directly apply eqn (12) and (13) with $\Delta G_{j}^{*}$ calculated within the capillarity approximation.

3.3.3 MKNT. The Mean-field Kinetic Nucleation Theory (MKNT) is based on a kinetics part following ref. 60 and on a statistical thermodynamics part with mean-field argument. ${ }^{14,15}$
The clusters are treated as core-shell particles assuming bulk liquid properties for the core and microscopic properties for the surface. Following the derivation in ref. 15, the nucleation rate is given by:

$$
J_{\mathrm{MKNT}}=A_{\mathrm{kin}}\left(\sum_{n=1}^{\infty} \mathrm{e}^{-H(n)}\right)^{-1}
$$

The exponential part of the equation is given by $-H(n)=$

$$
-n \ln S+\theta_{\text {micro }}\left[n^{s}(n)-1\right]-\ln \left[\sqrt{1+1 / n} \cdot\left(1+n^{1 / 3}\right)^{2} \cdot \frac{1}{1+\delta_{1 n}}\right]
$$

for a cluster with $n$ molecules and $n^{s}$ surface molecules. The last term in $-H(n)$ includes the dependence of $k_{1 n \text {,Hs }}$ on the cluster size $n$. $\theta_{\text {micro }}=-\ln \left(\frac{-B_{2} p_{\mathrm{eq}}(T)}{k_{\mathrm{B}} T}\right)$ is the microscopic surface tension using the second virial coefficient $B_{2}$. The kinetic prefactor $A_{\text {kin }}$ is calculated as follows: $A_{\text {kin }}=\frac{N_{1} p_{\mathrm{eq}}(T) s_{1}}{\sqrt{2 \pi m k_{\mathrm{B}} T}}, m$ is the monomer mass, $s_{1}$ is the surface area of the monomer and $p_{\text {eq }}$ is the equilibrium vapor pressure. The formulae used for the thermodynamic properties of $\mathrm{CO}_{2}$ and $\mathrm{C}_{3} \mathrm{H}_{8}$ can be found in the ESI. $f$

3.3.4 Nucleation rates using $\Delta G$ from DFT calculations. The framework of CNT can be combined with DFT calculations of the cluster Gibbs energy of formation to yield a more accurate nucleation rate. We refer to this nucleation rate as $J_{\mathrm{QM}}$ (see ref. 16). This approach avoids the application of the capillarity approximation to small clusters by directly calculating $\Delta G_{j}^{*}$. By inserting the relation of detailed balance (eqn (13) $)^{59}$ into eqn (12) we obtain:

$$
J_{\mathrm{QM}}=\frac{N_{1}^{2}}{\frac{1}{k_{11}}+\frac{\exp \left(\frac{\Delta G_{2}{ }^{*}}{k_{\mathrm{B}} T}\right)}{S k_{12}}+\frac{\exp \left(\frac{\Delta G_{3}{ }^{*}}{k_{\mathrm{B}} T}\right)}{S^{2} k_{13}}+\ldots}
$$

The uncertainty of $J_{\mathrm{QM}}$ mainly arises from the inaccuracies of the DFT calculations, which are discussed in more detail in the ESI. $\dagger$ Analogous to CNT and MKNT, we assume the high pressure limit of association kinetics for $J_{\mathrm{QM}}$, which might not hold for the present experimental conditions.

\subsection{DFT calculations}

The Gaussian09 program package ${ }^{61}$ was used for all DFT calculations. The starting geometries for the DFT calculations of the $\mathrm{CO}_{2}$ clusters were taken from our previous publication, ${ }^{28}$ which used the M06-2X functional ${ }^{62}$ and $6-31+G(d)$ basis set. For the calculation of $J_{\mathrm{QM}}$ (see Section 3.3.4) these were further refined using the same M06-2X functional, but a larger, correlation-consistent basis-set (aug-cc-pVTZ). ${ }^{63}$ The Gibbs free energy change $\Delta G_{j}^{*}$ associated with the reaction $j \cdot \mathrm{CO}_{2} \rightarrow\left(\mathrm{CO}_{2}\right)_{j}$ was calculated for all temperatures (Table 1 and Table SI, ESI $\dagger$ ) using zero-point and thermal corrections, and applying a scaling factor of 0.956 for the vibrational frequencies. ${ }^{64}$ As already discussed in ref. 29 , Lemke et $a l .{ }^{65}$ showed that the M06-2X functional is appropriate for dispersion bound systems 
and the extracted energies are consistent with $\operatorname{CCSD}(\mathrm{T})$ level calculations. Our calculations are in good agreement with previous studies. ${ }^{65,66}$ The refined structures and $\Delta G_{j}^{*}$ for cluster sizes $j=2-12$ are provided in the ESI. $\dagger$

\section{Results and discussion}

\subsection{Mass spectra and kinetic modeling}

Fig. 2 shows mass spectra as a function of the nucleation time for a low $\mathrm{CO}_{2}$ concentration $\left(0.12 \%\right.$, a) and a high $\mathrm{CO}_{2}$ concentration $(10 \%$, b) (see Table 1 for conditions). The maximal cluster sizes $n_{\text {max }}$ are indicated by arrows in Fig. $2 \mathrm{a}$ and $\mathrm{b}$. The spectra are background corrected for clarity. For both conditions, $n_{\max }=1$ is observed at the shortest time $(44 \mu \mathrm{s}$ and $36 \mu \mathrm{s}$, respectively). At a lower concentration (Fig. 2a), only small clusters are observed even for long nucleation times (maximal cluster size $n_{\max } \sim 40$ at $t=196 \mu \mathrm{s}$ ). A similar
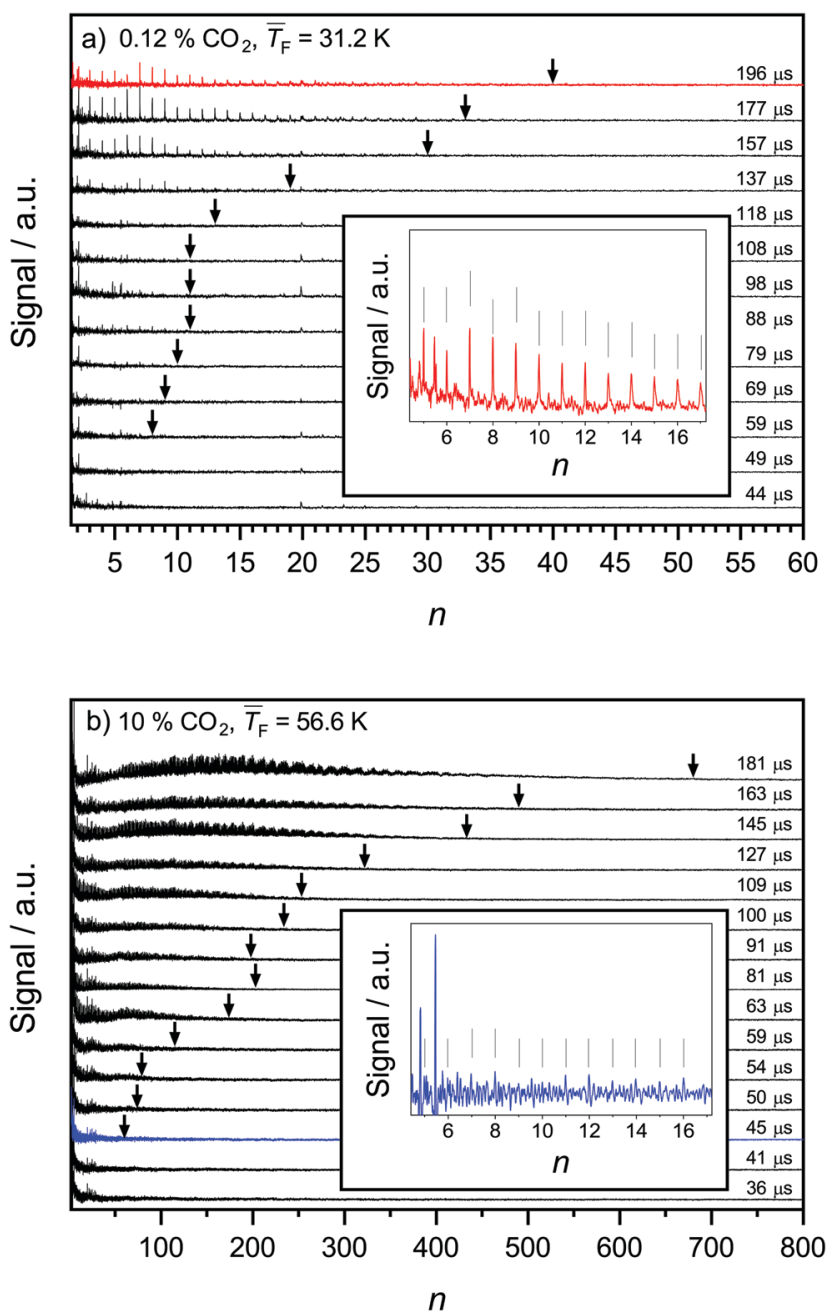

Fig. $2 \mathrm{CO}_{2}$ mass spectra as a function of the cluster size $n$ and nucleation time $t$ : (a) $0.12 \% \mathrm{CO}_{2}$ at a flow temperature of $31.2 \mathrm{~K}$ and (b) $10 \% \mathrm{CO}_{2}$ at a flow temperature of $56.6 \mathrm{~K}$. Further information can be found in Table 1. The mass spectra for these two temperatures exhibit a distinctly different temporal evolution. The insets show selected mass spectra with similar $n_{\text {max }}$ values: $0.12 \% \mathrm{CO}_{2}$ at $196 \mu$ s (red, a) and $10 \% \mathrm{CO}_{2}$ at $45 \mu$ s (blue, b). behavior was observed for water nucleation in our previous publication. ${ }^{28}$ At a higher concentration (Fig. 2b), very large clusters with several hundred molecules $\left(n_{\max }\right.$ up to $\sim 700$ ) are observed at long nucleation times. The explanation for this huge increase in $n_{\max }$ is the higher $\mathrm{CO}_{2}$ content which leads to faster cluster growth. The insets in Fig. 2a and b show zoom-ins of the $0.12 \% \mathrm{CO}_{2}$ mass spectrum recorded at $196 \mu \mathrm{s}$ (red, Fig. 2a) and the $10 \% \mathrm{CO}_{2}$ mass spectrum recorded at $45 \mu \mathrm{s}$ (blue, Fig. 2b). These spectra are chosen for comparison because their $n_{\max }$ values are relatively close. A comparison reveals that the very small clusters $(n<15)$ are much less intense for the high $\mathrm{CO}_{2}$ concentration (blue trace) than for the low $\mathrm{CO}_{2}$ concentration (red trace). For the larger clusters ( $n \geq 15$ ), this difference is less pronounced. The diminished intensity of the very small clusters for $10 \% \mathrm{CO}_{2}$ might hint at evaporation of these very small clusters. ${ }^{67}$ This hypothesis will be evaluated in more detail in Sections 4.3 and 4.4. As already discussed in ref. 29, we observe shell and subshell closings in the $\mathrm{CO}_{2}$ mass spectra for cluster sizes larger than 50-100, which allows us to directly extract the structure of the clusters. ${ }^{68-70}$ For all our conditions, cuboctahedral structures are observed (no structural change with increasing temperature). Representative mass spectra of $\mathrm{C}_{3} \mathrm{H}_{8}$ are shown in the ESI $\dagger$ (Fig. S2). They show a similar behavior as the $\mathrm{CO}_{2}$ mass spectra in Fig. 2 a.

\subsection{Fit of the net forward rate constants}

Using the model in Section 3.1, we can directly fit net forward rate constants $k_{1 j \text {,net }}$ to the experimental cluster size distributions retrieved from the mass spectra (Fig. 2, see Section 3.1 and the ESI $\dagger$ for fits). The extracted net forward rate constants for $\mathrm{CO}_{2}$ and $\mathrm{C}_{3} \mathrm{H}_{8}$ are shown in Fig. 3a and b, respectively. The monomer-monomer net forward rate constant $k_{11 \text {,net }}$ will be discussed in Section 4.4. Note that $k_{1 j \text {,net }}$ gives information about the balance of the association rate, determined by $k_{1 j}$, and the evaporation rate, determined by $E_{j+1}$, but it cannot provide information about their absolute values. For both substances, $\mathrm{CO}_{2}$ and $\mathrm{C}_{3} \mathrm{H}_{8}$, the net forward rate constants generally increase for larger cluster sizes (Fig. 3). There are two possible explanations for this: Firstly, the collision cross section increases with increasing cluster size. Secondly, for smaller clusters the evaporation rate is likely higher and the sticking probability is likely lower. The latter could be attributed to the smaller density of states in smaller clusters. This makes the distribution of the excess energy upon collision less efficient and leads to a lower sticking probability, resulting in a lower forward rate constant for smaller clusters. The retrieved $k_{1 j \text {,net }}$ values increase with decreasing temperature for both $\mathrm{CO}_{2}$ and $\mathrm{C}_{3} \mathrm{H}_{8}$ (Fig. 3). At first sight, this seems counter-intuitive because the hard sphere collision rate constant (eqn (5)) increases with increasing temperature. This observation is further discussed in Section 4.3.

\subsection{Enhancement factors}

The experimental net association rate constant $k_{1 j \text {,net }}$ (eqn (3)) embodies the net effect of three different processes: (a) monomer-cluster collision (capture), (b) monomer-cluster sticking 

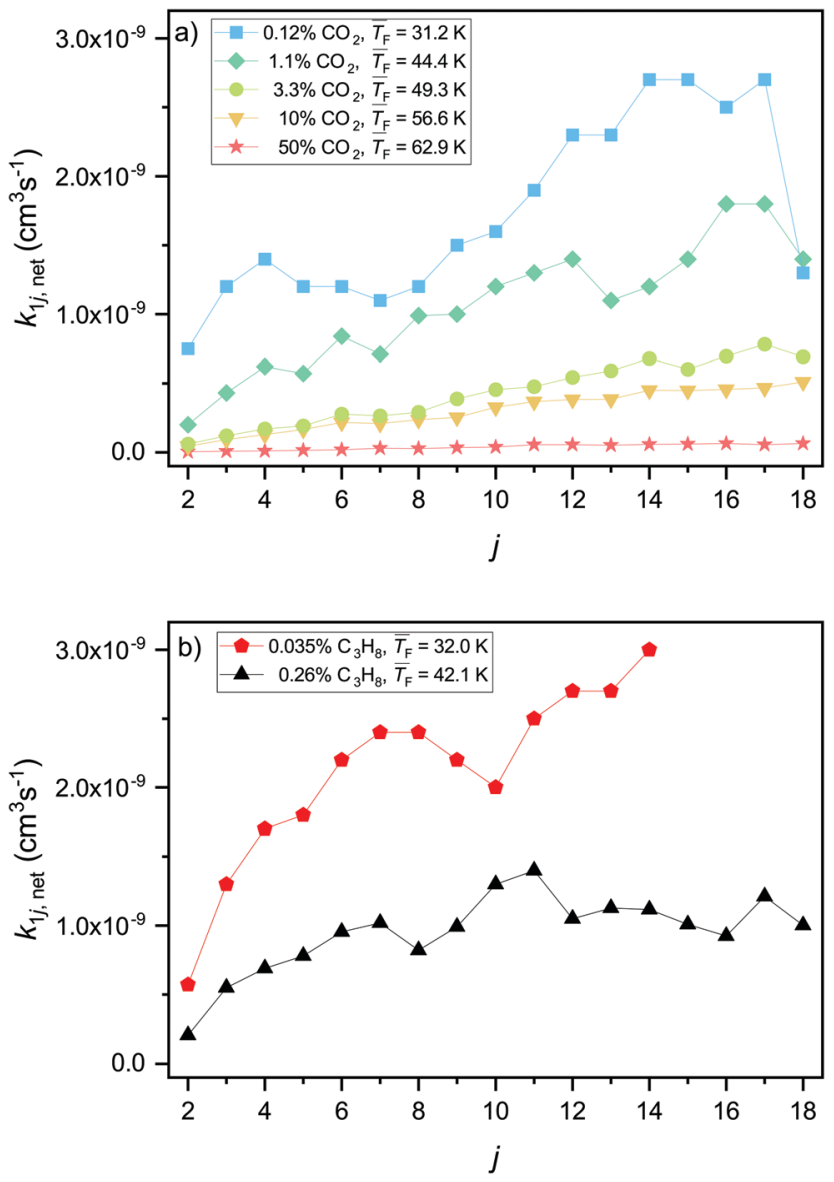

Fig. 3 Net forward rate constants $k_{1 j \text {,net }}$ of $\mathrm{CO}_{2}$ (a) and $\mathrm{C}_{3} \mathrm{H}_{8}$ (b) for $j \geq 2$. The net forward rate constants combine the contributions from association and evaporation.

and (c) cluster evaporation. The enhancement factor $\eta_{\exp }$ gives the ratio of the aforementioned net forward rate constants and the hard sphere collision rate constants $k_{1 j, \mathrm{HS}}$ (see Section 3.2). In the limit of unit sticking probability and negligible evaporation (barrierless), $k_{1 j \text {,net }}$ should be higher than $k_{1 j, \mathrm{HS}}$, because of the long-range interactions between the colliding entities, leading to $\eta_{\exp }>1$. A value of $\eta_{\exp }<1$ thus indicates non-unit sticking probability or cluster evaporation. In the following, $\eta_{\exp }$ is utilized as an indicator to analyze how the nucleation process changes as a function of the temperature by comparison with $\eta_{\text {calc. }} \eta_{\text {exp }}$ is shown in Fig. 4a for $\mathrm{CO}_{2}$ and in Fig. $4 \mathrm{~d}$ for $\mathrm{C}_{3} \mathrm{H}_{8}$. In both cases, $\eta_{\exp }$ decreases pronouncedly with increasing temperature. Fig. $4 \mathrm{~b}$ shows the calculated enhancement factor $\eta_{\text {calc }}$ for $\mathrm{CO}_{2}$ as described in Section 3.2. A comparison of the temperature dependence of $\eta_{\text {calc }}$ and $\eta_{\exp }$ for two selected cluster sizes is shown in Fig. 4c. The calculations for $\mathrm{CO}_{2}$ (panel $\mathrm{b}$ and $\mathrm{c}$ ) predict only a small decrease in $\eta_{\text {calc }}$ with increasing temperature, which is consistent with a $T^{-1 / 3}$ dependence of $k_{1 j \text {,inter }}$ This is expected for long-range interactions in collisions of non-polar molecules. ${ }^{50}$ The $T^{-1 / 3}$ dependence is indicated in Fig. $4 \mathrm{c}$ as a dashed red line. $\eta_{\exp }$ shows a far stronger temperature dependence, spanning two orders of magnitude for temperatures between $31.2 \mathrm{~K}$ and
$62.9 \mathrm{~K}$. Averaged over all $j, \eta_{\text {exp }}$ surpasses $\eta_{\text {calc }}$ by only a factor of $\sim 2.5$ at $31.2 \mathrm{~K}$ and by only a factor of $\sim 1.3$ at $44.4 \mathrm{~K}$, showing a general good agreement between experiment and calculation for the two lowest temperatures. At the highest temperature, by contrast, $\eta_{\text {calc }}$ is up to two orders of magnitude larger than $\eta_{\text {exp }}$. Furthermore, $\eta_{\exp }$ is strongly cluster size dependent at high temperatures, while the model predicts an approximately constant enhancement as a function of $j$ for all temperatures (see Fig. 4b). These differences point towards a fundamental change in the nucleation kinetics with increasing temperature as will be discussed below.

The pronounced increase of $\eta_{\exp }$ from $j=2$ to about $j=6$ (Fig. 4a) for all but the coldest temperature indicates a low sticking efficiency and/or high evaporation rate for smaller clusters. With increasing temperature, $\eta_{\exp }$ falls off rapidly for small cluster sizes and thus increasingly deviates from $\eta_{\text {calc }}$ (blue line in Fig. 4c), supporting this interpretation. It is, however, difficult to disentangle possible contributions from the low sticking efficiency and the evaporation rate. As discussed before, compared with larger clusters smaller clusters have fewer degrees of freedom to distribute the excess collision energy, which results in a decreased sticking efficiency. For larger clusters (green line in Fig. 4c) many degrees of freedom are available, making a low sticking efficiency less likely than for small clusters. Therefore, the strong deviation between $\eta_{\exp }$ and $\eta_{\text {calc }}$ even for larger cluster sizes rather hints that increasing evaporation rates are responsible for the observed deviations with increasing temperature. Non-negligible evaporation at higher temperatures implies a change from barrierless nucleation at $31.2 \mathrm{~K}$ to barrier-limited nucleation at higher temperatures.

The experimental enhancement for $\mathrm{C}_{3} \mathrm{H}_{8}$ (Fig. 4d) is roughly constant for all cluster sizes at a specific flow temperature, except for $j=2$ where $\eta_{\text {exp }}$ is significantly lower. The increase by $\sim 10 \mathrm{~K}$ from $32.0 \mathrm{~K}$ to $42.1 \mathrm{~K}$ leads to a decreased $\eta_{\exp }$ by approximately a factor of three averaged over all $j$. For both temperatures studied for $\mathrm{C}_{3} \mathrm{H}_{8}$, we find a similar behavior to that for $\mathrm{CO}_{2}$ at $31.2 \mathrm{~K}$, indicating barrierless nucleation for $\mathrm{C}_{3} \mathrm{H}_{8}$ at both temperatures.

In our previous work on water nucleation, ${ }^{30}$ cluster evaporation was found to be negligible up to $87 \mathrm{~K}$. While negligible evaporation at these low temperatures seems reasonable for strongly hydrogenbonded water clusters, this is no longer the case for weakly bound $\mathrm{CO}_{2}$ clusters - in agreement with the evidence for non-negligible evaporation for the $\mathrm{CO}_{2}$ clusters described above (see also the further discussions in Section 4.4).

\subsection{Nucleation rates of $\mathrm{CO}_{2}$}

Fig. 5a shows the total cluster number concentrations for $n>1$ as a function of the nucleation time for the five $\mathrm{CO}_{2}$ concentrations examined in this study. The experimental nucleation rates $J$ were determined by linear fitting of these data (eqn (2)). $J$ is shown in Table 1 and Fig. 5 b. Except for $50 \% \mathrm{CO}_{2}$ and $\overline{T_{\mathrm{F}}}=62.9 \mathrm{~K}$, there seems to be a small increase in $J$ with increasing flow temperature (from $1.5 \times 10^{15} \mathrm{~cm}^{-3} \mathrm{~s}^{-1}$ for $0.12 \% \mathrm{CO}_{2}$ and $\overline{T_{\mathrm{F}}}=31.2 \mathrm{~K}$ to $4.0 \times 10^{15} \mathrm{~cm}^{-3} \mathrm{~s}^{-1}$ for $10 \% \mathrm{CO}_{2}$ 

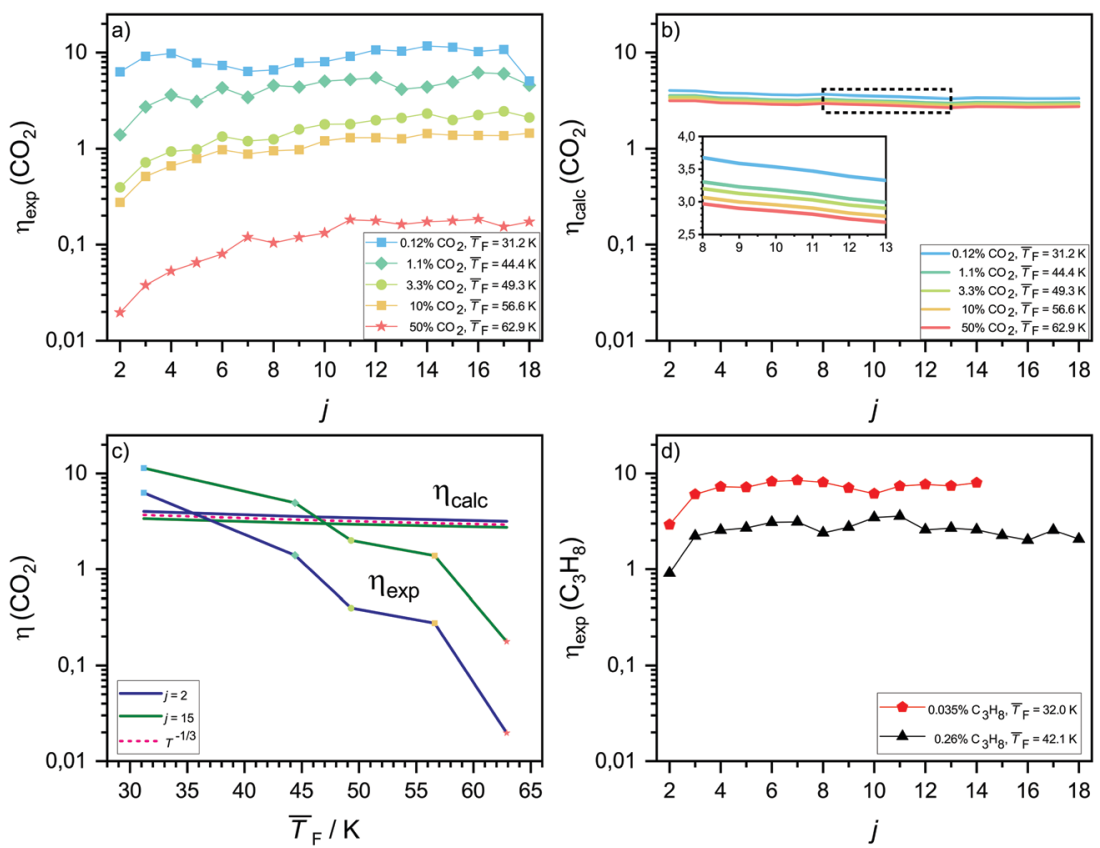

Fig. 4 (a) Experimental $\eta_{\exp }$ and (b) calculated $\eta_{\text {calc }}$ enhancement factors for a range of $\mathrm{CO}_{2}$ cluster sizes and five different temperatures. (c) Temperature dependence of $\mathrm{CO}_{2}$ enhancement factors for a small $(j=2)$ and a larger cluster size $(j=15)$. (d) $\eta_{\exp }$ for $\mathrm{C}_{3} \mathrm{H}_{8}$ as a function of the cluster size $j$.

and $\overline{T_{\mathrm{F}}}=56.6 \mathrm{~K}$ ), which, however, barely exceeds our relative experimental uncertainty. The issue with comparable $J$ values lies in its dependence on the monomer concentration $N_{1}$ which varies for different conditions (see Table 1 ). $k_{11 \text {,net }}$, by contrast, eliminates this dependence on $N_{1}$, providing a better comparison between the different conditions. Fig. $5 \mathrm{~b}$ shows that $k_{11 \text {,net }}$ decreases strongly by four orders of magnitude in the range from $31.2 \mathrm{~K}$ to $62.9 \mathrm{~K}$. Again, this decrease can be attributed to a lower sticking probability between monomers and/or a higher evaporation rate of dimers with increasing temperature. The decreased sticking probability should be most pronounced in monomer-monomer collisions. Even when evaporation rates are negligible and nucleation proceeds barrierless, $k_{11 \text {,net }}$ can be significantly smaller than $k_{11, \mathrm{HS}}$, indicating that dimer formation has not yet reached the high pressure limit. ${ }^{71}$

A direct comparison with previously published nucleation rates is not possible because all previous values were recorded at higher temperatures. At somewhat higher temperatures of $>70 \mathrm{~K}$, Wyslouzil and coworkers (Wyslouzil, BE, personal communication) found nucleation rates of $\sim 1 \times 10^{17} \mathrm{~cm}^{-3} \mathrm{~s}^{-1}$, i.e. rates that are $\sim 2$ orders of magnitude higher than the present rates $\left(\sim 1 \times 10^{15} \mathrm{~cm}^{-3} \mathrm{~s}^{-1}\right)$. Such an increase seems reasonable. Note that we cannot find overlap with their conditions because of experimental limitations in $t$ and $p_{\mathrm{F}} \cdot \mathrm{CO}_{2}$ nucleation was also studied by Duff ${ }^{72}$ in the temperature range between $160 \mathrm{~K}$ and $190 \mathrm{~K}$ and by Lettieri et $\mathrm{al}^{73}$ in the range between $260 \mathrm{~K}$ and $300 \mathrm{~K}$. These measurements lie far outside our experimental conditions and a comparison is thus not possible. For further analysis, we turn to comparisons with results from nucleation theories.

The predictions of the nucleation rate from CNT (Section 3.3.2) and from MKNT (Section 3.3.3) are shown in Table 1. The used thermodynamic properties of $\mathrm{CO}_{2}$ and $\mathrm{C}_{3} \mathrm{H}_{8}$ can be found in the ESI. $\dagger$ As expected, CNT yields the hard sphere collision limit $J_{\mathrm{HS}}$ or values very close to it, which lies 2 to 7 orders of magnitude above our experimental nucleation rates. MKNT has been shown to provide decent estimates for nucleation rates of $\mathrm{Ar}$ in the range of $\sim 34 \mathrm{~K}$ to $53 \mathrm{~K}$, with nucleation rates of $\sim 1 \times 10^{17} \mathrm{~cm}^{-3} \mathrm{~s}^{-1}$ and $\ln S$ of up to $\sim 10$ (see ref. 9). In the present study, $\ln S$ varies between $\sim 26$ and $\sim 78$. At such extreme supersaturations, MKNT fails to describe condensation accurately as it gives unreasonably low values. MKNT does not seem to describe the surface free energy of clusters properly for cluster sizes below the bulk coordination number. From the enhancement model outlined in Section 3.2, we can determine $J_{\text {inter }}$. The enhanced rates result in a nucleation rate which is roughly twice $J_{\mathrm{HS}}$ and therefore differs even further from the experimental $J$. The strong differences between $J$ and $J_{\text {inter }}$ for all conditions support a low sticking probability for monomer-monomer collisions.

As described in Section 3.3.4, we can use the kinetic framework of CNT and $\Delta G_{j}^{*}$ from DFT calculations to calculate $J_{\mathrm{QM}}$. The calculated values for $\Delta G_{j}^{*}$ can be found in the ESI. $\dagger J_{\mathrm{QM}}$ can be understood as a correction to the capillarity approximation in CNT using cluster formation energies. Cluster evaporation is explicitly considered here by using the method of detailed balance (see Section 3.3.4 and ref. 59), but the high pressure limit is still assumed, leading to a potential overestimation of the nucleation rate. Out of all calculated nucleation rates $J_{\mathrm{QM}}$ is the closest to our measured rates. Except for the highest temperature (Table 1), $J_{\mathrm{QM}}$ lies only around one magnitude above $J$, which lies within the experimental uncertainty. Nonunit sticking would lower $J_{\mathrm{QM}}$, and thus bring $J_{\mathrm{QM}}$ probably 

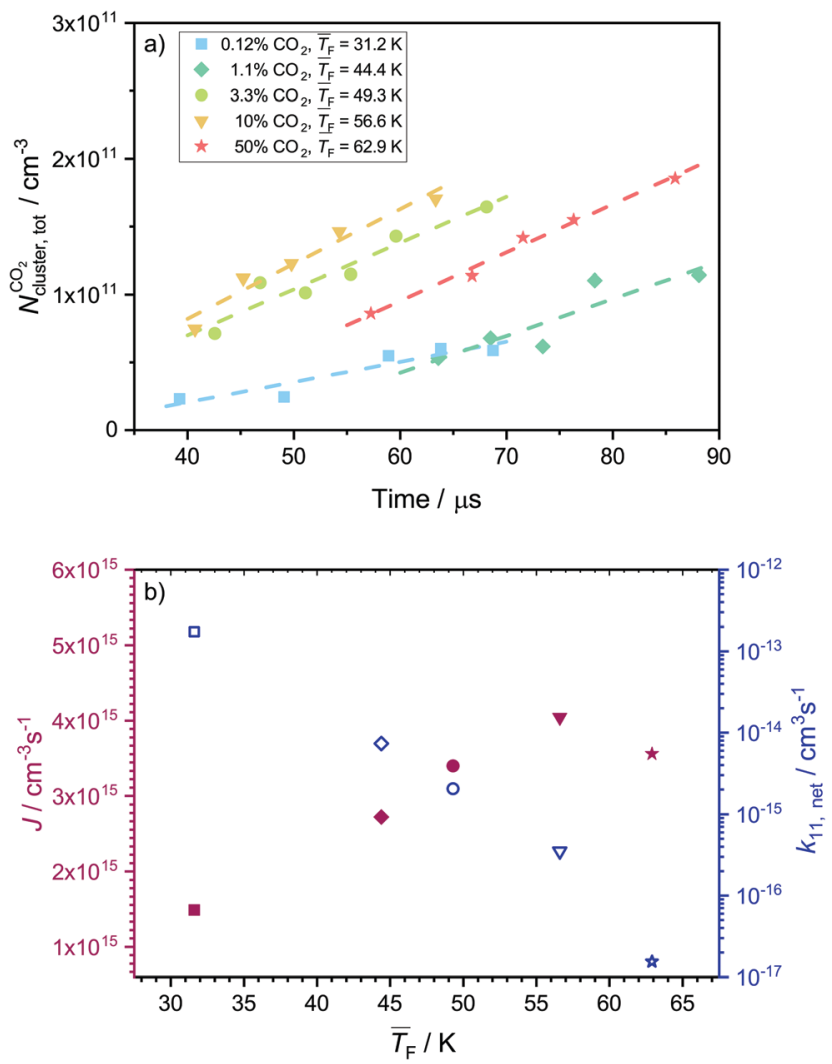

Fig. 5 (a) Total cluster number concentration as a function of time for $50 \%, 10 \%, 3.3 \% 1.13 \%$ and $0.12 \% \mathrm{CO}_{2}$. The linear fits are indicated with dashed lines. The data for $0.12 \% \mathrm{CO}_{2}$ were already published in our previous publication. ${ }^{29}$ (b) Experimental nucleation rate $J$ (full red symbols) and monomer-monomer net forward rate constants $k_{11 \text {,net }}$ (open blue symbols) extracted from the data shown in panel a. The use of the symbols is consistent in panels $a$ and $b$.

closer to $J$. However, it cannot completely be excluded that the good agreement between $J$ and $J_{\mathrm{QM}}$ could be coincidental because of the uncertainties of $J_{\mathrm{QM}}$ arising from the accuracy of the DFT calculations.

The DFT calculations predict negligible evaporation below $\sim 26 \mathrm{~K}$, but non-negligible evaporation above $\sim 26 \mathrm{~K}$ : at temperatures below $\sim 26 \mathrm{~K}, J_{\mathrm{QM}}$ is nearly identical to $J_{\mathrm{Hs}}$. This implies a transition from barrierless nucleation at $\sim 26 \mathrm{~K}$ to nucleation in the presence of a barrier above $\sim 26 \mathrm{~K}$. A sensitivity analysis of $J_{\mathrm{QM}}$ with respect to the uncertainty of $\Delta G_{j}^{*}$ reveals that a $5 \%$ change of $\Delta G_{j}^{*}$ results in a change in the nucleation rate of one to two orders of magnitude (see the ESI $\dagger$ for details). This in turn would convert into an uncertainty of the transition temperature (above which $J_{\mathrm{QM}}<0.9 \times J_{\mathrm{HS}}$ ) that ranges from $20.1 \mathrm{~K}$ to $30.8 \mathrm{~K}$ (see the ESI, $\dagger$ Fig. S7). The uncertainty of this transition region combined with our experimental uncertainties suggests that this region might indeed lie in the temperature range covered by our experiment.

From the DFT calculations, we can also gain information about the size of the critical nucleus. The largest term in the denominator of eqn (15) allows one to determine the critical cluster. At $62.9 \mathrm{~K}$ and $56.6 \mathrm{~K}$ the critical nucleus is a trimer, while at $49.3 \mathrm{~K}$ and $44.4 \mathrm{~K}$ a transition to the dimer seems to occur (note that the corresponding terms are very close in magnitude, which impedes a definite assignment). At the lowest temperature of $31.2 \mathrm{~K}$, the critical nucleus is either a dimer or a monomer. These terms are very sensitive to the value of $\Delta G_{j}^{*}$, therefore the uncertainty of the size of the critical nucleus is large, analogous to the uncertainty of the transition temperature. Nevertheless, the calculations show a clear trend towards the emergence of a nucleation barrier at higher temperatures.

\subsection{Nucleation rates of $\mathrm{C}_{3} \mathrm{H}_{8}$}

Fig. $6 \mathrm{a}$ and $\mathrm{b}$ show the total cluster number concentrations as a function of time and the extracted $J$ and $k_{11 \text {,net }}$, respectively, for $\mathrm{C}_{3} \mathrm{H}_{8}$. The values of $\overline{T_{\mathrm{F}}}$ and $p_{\mathrm{F}}$ are very similar for $0.12 \% \mathrm{CO}_{2}$ and for $0.035 \% \mathrm{C}_{3} \mathrm{H}_{8}$ as well as for $1.1 \% \mathrm{CO}_{2}$ and for $0.26 \%$ $\mathrm{C}_{3} \mathrm{H}_{8}$. The fact that both $\mathrm{C}_{3} \mathrm{H}_{8}$ concentrations are lower demonstrates that $\mathrm{C}_{3} \mathrm{H}_{8}$ nucleates more easily than $\mathrm{CO}_{2}$ under otherwise similar conditions. The values of $J$ are of the same order of magnitude as those for $\mathrm{CO}_{2}$ (Table 1). The two data points in Fig. $6 \mathrm{~b}$ seem to imply a decrease of $J$ with decreasing temperature, which would be opposite to the behavior of $\mathrm{CO}_{2}$ (Section 4.4).
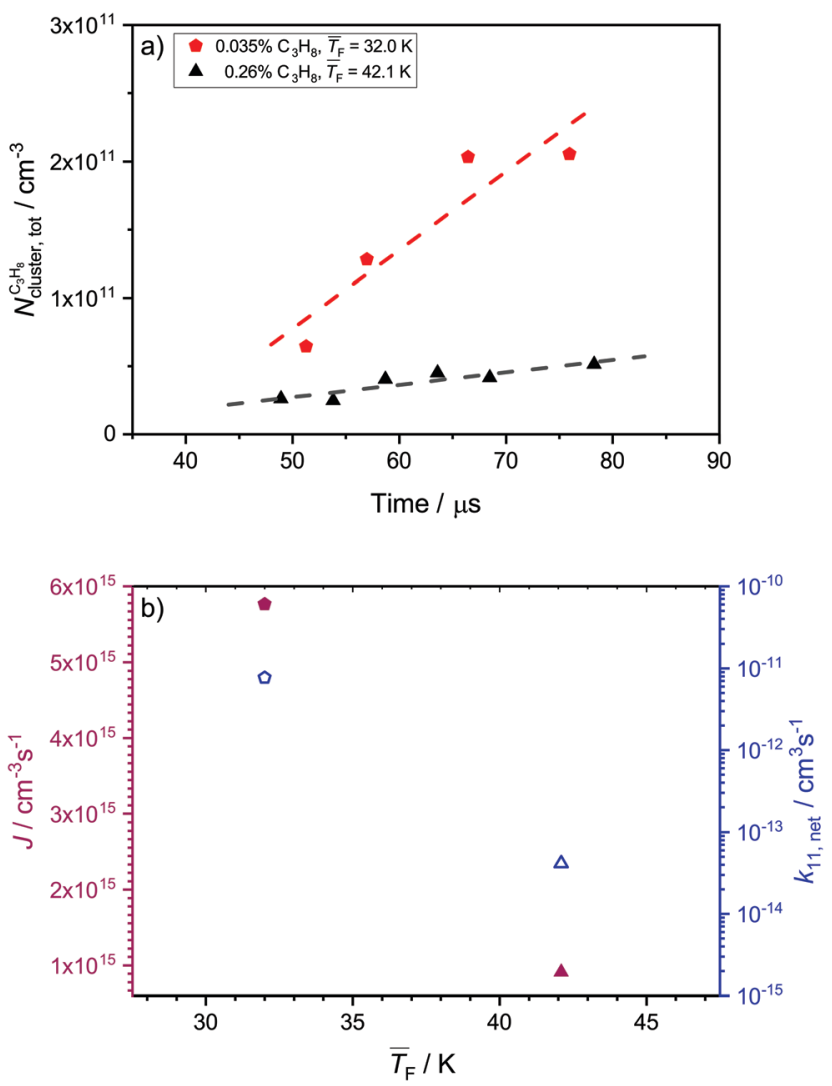

Fig. 6 (a) Total cluster number concentration as a function of time for $0.035 \%$ and $0.26 \% \mathrm{C}_{3} \mathrm{H}_{8}$. The linear fits are indicated with dashed lines. (b) Experimental nucleation rates $J$ (full red symbols) and monomermonomer net forward rate constants $k_{11 \text {, net }}$ (open blue symbols) extracted from the $\mathrm{C}_{3} \mathrm{H}_{8}$ data in panel a as a function of the flow temperature. The data for $0.26 \% \mathrm{C}_{3} \mathrm{H}_{8}$ are shown as up triangles and those for $0.035 \% \mathrm{C}_{3} \mathrm{H}_{8}$ as pentagons. 
However, one needs to keep in mind that a clear trend cannot be extracted from only two data points.

To the best of our knowledge, these are the first experimental nucleation rates for $\mathrm{C}_{3} \mathrm{H}_{8}$, so that a comparison with previous experimental data is not possible. However, we can compare the experimental rates with the predictions from the models (see Table 1). As discussed in Section 4.4 for $\mathrm{CO}_{2}$, CNT gives the hard sphere collision limit or values close to it and MKNT gives unreasonably low values. Both theories thus fail in describing $J$ for our conditions for both $\mathrm{CO}_{2}$ and $\mathrm{C}_{3} \mathrm{H}_{8}$. Because of the many isomers of $\mathrm{C}_{3} \mathrm{H}_{8}$ clusters, ${ }^{52}$ we do not calculate $J_{\mathrm{QM}}$. Only the monomer-monomer collision rate $k_{11 \text {,inter }}$ is evaluated, yielding values for $J_{\text {inter }}$ which are about two times larger than $J_{\mathrm{HS}}$. This enhancement of the nucleation rate is comparable to that for $\mathrm{CO}_{2}$, which seems reasonable as both substances form weakly bound clusters. As in the case of $\mathrm{CO}_{2}, k_{11 \text {,net }}$ decreases with increasing temperature and lies far below the theoretical monomermonomer collision rate constants. This can again be attributed to a lower sticking probability at higher temperatures. In Section 4.3, we found that $\eta_{\exp }>1$ for $\mathrm{C}_{3} \mathrm{H}_{8}$, which suggests that nucleation is likely barrierless under both conditions studied here.

\subsection{Third body interaction}

The carrier gas is expected to have two main influences on nucleation. Firstly, it removes the latent heat which is released during nucleation (thermalization) and secondly, the clusters have to spend volume work to grow in the presence of the carrier gas. Both factors strongly depend on the pressure and type of carrier gas. ${ }^{74}$ At low absolute pressures, the thermalization effect should dominate leading to a positive pressure effect (increase of the nucleation rate with increasing pressure). At high absolute pressures though, the volume work effect should dominate leading to a negative pressure effect (decrease of the nucleation rate with increasing pressure). Several experimental and theoretical studies have investigated the effect of the total pressure on nucleation. ${ }^{75-79}$ The findings of the different studies are very ambiguous. Positive, negative and no pressure dependence was found for various substances and experimental conditions.

To test the influence of the carrier gas, we change the flow pressure $p_{\mathrm{F}}$ while keeping $p_{\mathrm{CO}_{2}}$ and $\overline{T_{\mathrm{F}}}$ constant (see Table 2 ). Note that $p_{\mathrm{F}}$ can only be changed in a small window because the uniformity of the postnozzle flow has to be maintained. To do so, the carrier gas composition (ratio of $\mathrm{Ar}$ to $\mathrm{CH}_{4}$ ) is slightly varied. Fig. 7 shows the total cluster number concentration as a function of the nucleation time for three different values of $p_{\mathrm{F}}$ for $\mathrm{CO}_{2}$. The corresponding nucleation rates $J$ are also indicated in the figure (see also Table 2). The nucleation rate $J$ increases with increasing $p_{\mathrm{F}}$. Assuming a relative error in $J$ of a factor of two, the increase in $J$ is outside our experimental uncertainty for the increase from 22.5 or $30 \mathrm{~Pa}$ to $37 \mathrm{~Pa}$. This hints at a positive pressure effect, which appears reasonable in this low pressure regime. ${ }^{74}$ The arrows in Fig. 7 indicate the onset times of nucleation. A comparison of the onset times shows that the higher the $p_{\mathrm{F}}$, the earlier the nucleation takes place in the postnozzle flow. This indicates that a higher $p_{\mathrm{F}}$ accelerates nucleation.
Table 2 List of the experimental parameters for the data shown in Fig. 7. The definitions of nozzle, $p_{\mathrm{CO} z}, p_{\mathrm{F}}, \% \mathrm{Ar}, \% \mathrm{CH}_{4}, \bar{M}, \overline{T_{\mathrm{F}}}$ and $\mathrm{J}$ are given in the caption of Table 1

\begin{tabular}{|c|c|c|c|}
\hline & $1.5 \% \mathrm{CO}_{2}$ & $1.13 \% \mathrm{CO}_{2}$ & $0.91 \% \mathrm{CO}_{2}$ \\
\hline Symbol & $\Delta$ & 0 & $\mathbf{\square}$ \\
\hline Nozzle & Mach 5.2 & Mach 5.2 & Mach 6 \\
\hline$p_{\mathrm{CO}} / \mathrm{Pa}$ & 0.338 & 0.338 & 0.338 \\
\hline$p_{\mathrm{F}} / \mathrm{Pa}$ & 22.5 & 30 & 37 \\
\hline$\% \mathrm{CH}_{4}$ & 3.0 & 6.0 & 22.7 \\
\hline$\% \mathrm{Ar}$ & 95.5 & 92.9 & 76.4 \\
\hline$\overline{T_{\mathrm{F}}} / \mathrm{K}$ & $42.6 \pm 1.1$ & $43.0 \pm 1.4$ & $43.0 \pm 1.2$ \\
\hline $\bar{M}$ & $4.32 \pm 0.07$ & $4.35 \pm 0.08$ & $4.72 \pm 0.08$ \\
\hline$J / \mathrm{cm}^{-3} \mathrm{~s}^{-1}$ & $1.5 \times 10^{15}$ & $1.8 \times 10^{15}$ & $1.3 \times 10^{16}$ \\
\hline
\end{tabular}

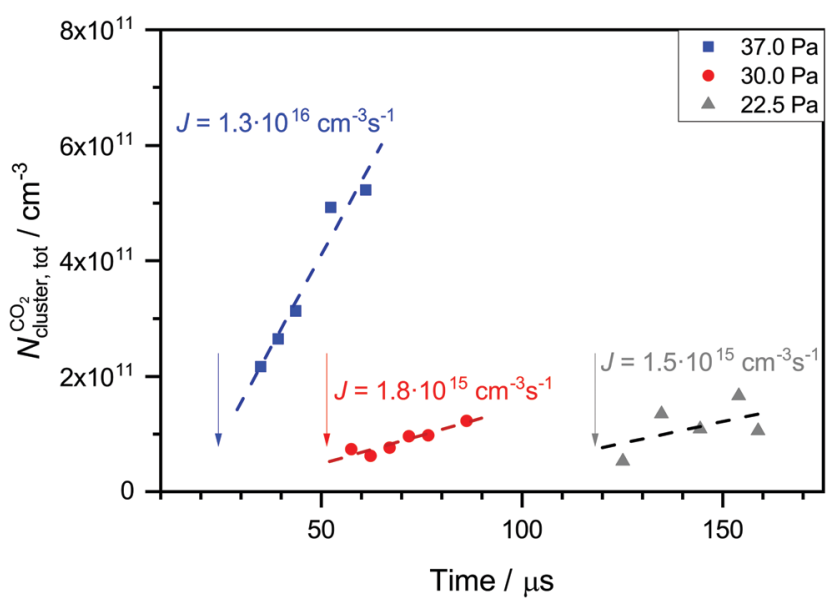

Fig. 7 Total cluster number concentrations as a function of time $t$ for identical $\mathrm{CO}_{2}$ pressure $p_{\mathrm{CO}_{2}}$ and the same flow temperatures $\overline{T_{\mathrm{F}}}(\sim 43 \mathrm{~K}$, but three different flow pressures of $p_{\mathrm{F}}$ : $22.5 \mathrm{~Pa}, 30 \mathrm{~Pa}$ and $37 \mathrm{~Pa}$ (see Table 2)). The arrows indicate the onset of nucleation. The dashed lines correspond to linear fits to the data. $J$ is the nucleation rate.

Since nucleation is also very sensitive to temperature, we have estimated the influence of the small temperature differences (see Table 2) on the value of $J$ by calculating $J_{\mathrm{HS}}$ and $J_{\mathrm{QM}}$ at slightly different temperatures. A variation in temperature between $41.6 \mathrm{~K}$ and $44.4 \mathrm{~K}$ corresponds to a change in $J_{\mathrm{HS}}$ of about $10 \%$ and a change in $J_{\mathrm{QM}}$ of around a factor of two. These changes are still too small to explain the observed increase of $J$ from 22.5 or $30 \mathrm{~Pa}$ to $37 \mathrm{~Pa}$. Slight variations in temperature or temperature fluctuations seem rather unlikely to be at the origin of the systematic changes in $J$ with $p_{\mathrm{F}}$.

As mentioned above, different carrier gas compositions were used for the measurements in Table 2. The $\mathrm{CH}_{4}$ content increases as $p_{\mathrm{F}}$ increases. As discussed in our previous publications ${ }^{28,30}$ and in the literature, ${ }^{76,77,80-82}$ the type of carrier gas might also have an influence on the nucleation rate. Dumitrescu et al. ${ }^{81}$ found better thermalization properties for $\mathrm{CH}_{4}$ compared with Ar. This suggests that a higher $\mathrm{CH}_{4}$ content would also lead to an increase in $J$. Thus, we cannot completely exclude that the change in the carrier gas composition also contributes to the observed increase in $J$. In any case, we find an increase in the nucleation rate with increasing flow pressure and changing carrier gas composition. 


\section{Conclusions}

In this work, we investigate homogeneous gas-phase nucleation of $\mathrm{CO}_{2}$ and $\mathrm{C}_{3} \mathrm{H}_{8}$ at high supersaturations in the temperature range from $\sim 31 \mathrm{~K}$ to $63 \mathrm{~K}$ and $\sim 32 \mathrm{~K}$ to $42 \mathrm{~K}$, respectively. This corresponds to a change in the partial pressure of the condensable by three orders of magnitude. The nucleation rate $J$ and the net forward rate constant $k_{1 j \text {,net }}$ (the net effect of association and evaporation processes) are directly retrieved from the experimental cluster size distributions recorded as a function of the nucleation time. For $\mathrm{CO}_{2}$, we observe an increase of $k_{1 j \text {,net }}$ with decreasing flow temperature $\overline{T_{\mathrm{F}}}$ even at high cluster size $j$, where the sticking probability is most likely close to 1 . This result hints at negligible evaporation for low temperature and non-negligible evaporation for high temperature, which implies a transition from barrierless nucleation at low $\overline{T_{\mathrm{F}}}$ to barrier-limited nucleation at higher $\overline{T_{\mathrm{F}}}$. However, the transition temperature cannot be determined definitively. Quantum-chemical calculations combined with the experimental results further indicate that this transition might lie within the temperature range investigated in the present study. Compared with other nucleation theories (CNT and MKNT), the quantum mechanics based nucleation rate, $J_{\mathrm{QM}}$, yields much better agreement with the experiment. The comparison between $\mathrm{CO}_{2}$ and $\mathrm{C}_{3} \mathrm{H}_{8}$ indicates that the nucleation of $\mathrm{C}_{3} \mathrm{H}_{8}$ is most likely barrierless for the conditions studied here. Nucleation rate measurements at different $p_{\mathrm{F}}$ show a slight increase of $J$ with increasing $p_{\mathrm{F}}$, suggesting that an increase of the flow pressure enhances nucleation. A more detailed description of the nucleation kinetics could be obtained from calculations of association and dissociation rate constants, analogous to those recently presented for $\mathrm{H}_{2} \mathrm{O}$ in ref. 71 , which could pinpoint the aforementioned transition more precisely.

\section{Conflicts of interest}

There are no conflicts to declare.

\section{Acknowledgements}

We are very grateful to Prof. Barbara Wyslouzil for many stimulating discussions and in particular for suggesting investigation of the pressure dependence of the nucleation rate. We also thank Markus Steger, David Stapfer and Dr Egor Chasovskikh for their help in maintaining the experimental setup. Financial support was provided by the Swiss National Science Foundation (SNF Project No. 200020-172472) and by ETH Zürich.

\section{References}

1 G. P. Sutton and O. Biblarz, Rocket propulsion elements, John Wiley \& Sons, 2016.

2 M. Kulmala, I. Riipinen, M. Sipilä, H. E. Manninen, T. Petäjä, H. Junninen, M. Dal Maso, G. Mordas, A. Mirme, M. Vana, A. Hirsikko, L. Laakso, R. M. Harroson, I. Hanson, C. Leung,
K. E. J. Lehtinen and V.-M. Kerminen, Science, 2007, 318, 89-92.

3 R. Zhang, Science, 2010, 328, 1366-1367.

4 C. I. Davidson, R. F. Phalen and P. A. Solomon, Aerosol Sci. Technol., 2005, 39, 737-749.

5 K.-H. Kim, E. Kabir and S. Kabir, Environ. Int., 2015, 74, 136-143.

6 B. E. Wyslouzil and J. Wölk, J. Chem. Phys., 2016, 145, 211702.

7 K. Iland, J. Wölk, R. Strey and D. Kashchiev, J. Chem. Phys., 2007, 127, 154506.

8 S. Sinha, H. Laksmono and B. Wyslouzil, Rev. Sci. Instrum., 2008, 79, 114101.

9 S. Sinha, A. Bhabhe, H. Laksmono, J. Wölk, R. Strey and B. Wyslouzil, J. Chem. Phys., 2010, 132, 064304.

10 L. M. Feldmar, J. Wölk and R. Strey, AIP Conf. Proc., 2013, 15-18.

11 D. Ghosh, D. Bergmann, R. Schwering, J. Wölk, R. Strey, S. Tanimura and B. E. Wyslouzil, J. Chem. Phys., 2010, 132, 024307.

12 K. Mullick, A. Bhabhe, A. Manka, J. Wolk, R. Strey and B. E. Wyslouzil, J. Phys. Chem. B, 2015, 119, 9009-9019.

13 J. Wölk, R. Strey, C. H. Heath and B. E. Wyslouzil, J. Chem. Phys., 2002, 117, 4954-4960.

14 V. I. Kalikmanov, J. Chem. Phys., 2006, 124, 124505.

15 V. I. Kalikmanov, Nucleation Theory, Springer, Netherlands, Heidelberg, 2013.

16 H. Du, A. B. Nadykto and F. Yu, Phys. Rev. E: Stat., Nonlinear, Soft Matter Phys., 2009, 79, 021604.

17 J. Diemand, R. Angélil, K. K. Tanaka and H. Tanaka, J. Chem. Phys., 2013, 139, 074309.

18 J. Merikanto, J. Duplissy, A. Määttänen, H. Henschel, N. M. Donahue, D. Brus, S. Schobesberger, M. Kulmala and H. Vehkamäki, J. Geophys. Res.: Atmos., 2016, 121, 1736-1751.

19 J. Duplissy, J. M. A. Franchin, G. Tsagkogeorgas, J. Kangasluoma, D. Wimmer, H. Vuollekoski, S. Schobesberger, K. Lehtipalo, R. C. Flagan, D. Brus, N. M. Donahue, H. Vehkamäki, J. Almeida, A. Amorim, P. Barmet, F. Bianchi, M. Breitenlechner, E. M. Dunne, R. Guida, H. Henschel, H. Junninen, J. Kirkby, A. Kürten, A. Kupc, A. Määttänen, V. Makhmutov, S. Mathot, T. Nieminen, A. Onnela, A. P. Praplan, F. Riccobono, L. Rondo, G. Steiner, A. Tome, H. Walther, U. Baltensperger, K. S. Carslaw, J. Dommen, A. Hansel, T. Petäjä, M. Sipilä, F. Stratmann, A. Vrtala, P. E. Wagner, D. R. Worsnop, J. Curtius and M. Kulmala, J. Geophys. Res.: Atmos., 2016, 121, 1752-1775.

20 L. Tiszenkel, C. Stangl, J. Krasnomowitz, Q. Ouyang, H. Yu, M. J. Apsokardu, M. V. Johnston and S.-H. Lee, Atmos. Chem. Phys., 2019, 19, 8915-8929.

21 C. F. Clement and I. J. Ford, Atmos. Environ., 1999, 33, 489-499.

22 Y. Viisanen, R. Strey, A. Laaksonen and M. Kulmala, J. Chem. Phys., 1994, 100, 6062-6072.

23 S. Tanimura, H. Pathak and B. E. Wyslouzil, J. Chem. Phys., 2013, 139, 174311. 
24 B. Schläppi, J. H. Litman, J. J. Ferreiro, D. Stapfer and R. Signorell, Phys. Chem. Chem. Phys., 2015, 17, 25761-25771.

25 J. J. Ferreiro, T. E. Gartmann, B. Schläppi and R. Signorell, Z. Phys. Chem., 2015, 229, 1765-1780.

26 J. J. Ferreiro, S. Chakrabarty, B. Schläppi and R. Signorell, J. Chem. Phys., 2016, 145, 211907.

27 S. Chakrabarty, J. J. Ferreiro, M. Lippe and R. Signorell, J. Phys. Chem. A, 2017, 121, 3991-4001.

28 M. Lippe, S. Chakrabarty, J. J. Ferreiro, K. K. Tanaka and R. Signorell, J. Chem. Phys., 2018, 149, 244303.

29 M. Lippe, U. Szczepaniak, G.-L. Hou, S. Chakrabarty, J. J. Ferreiro, E. Chasovskikh and R. Signorell, J. Phys. Chem. A, 2019, 123, 2426-2437.

30 C. Li, M. Lippe, J. Krohn and R. Signorell, J. Chem. Phys., 2019, 151, 094305.

31 F. Gelbard and J. H. Seinfeld, J. Colloid Interface Sci., 1979, 68, 363-382.

32 B. L. Yoder, J. H. Litman, P. W. Forysinski, J. L. Corbett and R. Signorell, J. Phys. Chem. Lett., 2011, 2, 2623-2628.

33 J. H. Litman, B. L. Yoder, B. Schläppi and R. Signorell, Phys. Chem. Chem. Phys., 2013, 15, 940-949.

34 S. Heinbuch, F. Dong, J. J. Rocca and E. R. Bernstein, J. Chem. Phys., 2006, 125, 154316.

35 J. Lengyel, A. Pysanenko, J. Kočišek, V. Poterya, C. C. Pradzynski, T. Zeuch, P. Slavíček and M. Fárník, J. Phys. Chem. Lett., 2012, 3, 3096-3101.

36 J. Lengyel, A. Pysanenko, V. Poterya, J. Kočišek and M. Fárnk, Chem. Phys. Lett., 2014, 612, 256-261.

37 K. Kameta, N. Kouchi, M. Ukai and Y. Hatano, J. Electron Spectrosc. Relat. Phenom., 2002, 123, 225-238.

38 J. W. Au, G. Cooper and C. E. Brion, Chem. Phys., 1993, 173, 241-265.

39 M. Ruberti, R. Yun, K. Gokhberg, S. Kopelke, L. S. Cederbaum, F. Tarantelli and V. Averbukh, J. Chem. Phys., 2013, 139, 144107.

40 R. M. Stephenson and S. Malanowski, Handbook of the thermodynamics of organic compounds, Elsevier Science Publishing Co., Inc., 1987.

41 R. Stockbauer and M. G. Inghram, J. Chem. Phys., 1971, 54, 2242-2246.

42 W. F. Giauque and C. J. Egan, J. Chem. Phys., 1937, 5, 45-54.

43 J. H. Seinfeld and S. N. Pandis, Atmospheric chemistry and physics: from air pollution to climate change, John Wiley \& Sons, Inc., 2016.

44 R. Halonen, E. Zapadinsky, T. Kurtén, H. Vehkamäki and B. Reischl, Atmos. Chem. Phys., 2019, 19, 13355-13366.

45 A. Kürten, C. Li, F. Bianchi, J. Curtius, A. Dias, N. M. Donahue, J. Duplissy, R. C. Flagan, J. Hakala, T. Jokinen, J. Kirkby, M. Kulmala, A. Laaksonen, K. Lehtipalo, V. Makhmutov, A. Onnela, M. P. Rissanen, M. Simon, M. Sipilä, Y. Stozhkov, J. Tröstl, P. Ye and P. H. McMurry, Atmos. Chem. Phys., 2018, 18, 845-863.

46 A. Kürten, T. Jokinen, M. Simon, M. Sipilä, N. Sarnela, H. Junninen, A. Adamov, J. Almeida, A. Amorim, F. Bianchi, M. Breitenlechner, J. Dommen, N. M. Donahue, J. Duplissy, S. Ehrhart, R. C. Flagan, A. Franchin, J. Hakala, A. Hansel, M. Heinritzi, M. Hutterli, J. Kangasluoma,
J. Kirkby, A. Laaksonen, K. Lehtipalo, M. Leiminger, V. Makhmutov, S. Mathot, A. Onnela, T. Petäjä, A. P. Praplan, F. Riccobono, M. P. Rissanen, L. Rondo, S. Schobesberger, J. H. Seinfeld, G. Steiner, A. Tomé, J. Tröstl, P. M. Winkler, C. Williamson, D. Wimmer, P. Ye, U. Baltensperger, K. S. Carslaw, M. Kulmala, D. R. Worsnop and J. Curtius, Proc. Natl. Acad. Sci. U. S. A., 2014, 111, 15019-15024.

47 K. Lehtipalo, L. Rondo, J. Kontkanen, S. Schobesberger, T. Jokinen, N. Sarnela, A. Kürten, S. Ehrhart, A. Franchin, T. Nieminen, F. Riccobono, M. Sipilä, T. Yli-Juuti, J. Duplissy, A. Adamov, L. Ahlm, J. Almeida, A. Amorim, F. Bianchi, M. Breitenlechner, J. Dommen, A. J. Downard, E. M. Dunne, R. C. Flagan, R. Guida, J. Hakala, A. Hansel, W. Jud, J. Kangasluoma, V.-M. Kerminen, H. Keskinen, K. Jaeseok, J. Kirkby, A. Kupc, O. Kupiainen-Määttä, A. Laaksonen, M. J. Lawler, M. Leiminger, S. Mathot, T. Olenius, I. K. Ortega, A. Onnela, T. Petäjä, A. Praplan, M. P. Rissanen, T. Ruuskanen, F. D. Santos, S. Schallhart, R. Schnitzhofer, M. Simon, J. N. Smith, J. Tröstl, G. Tsagkogeorgas, A. Tomé, P. Vaattovaara, H. Vehkamäki, A. E. Vrtala, P. E. Wagner, C. Williamson, D. Wimmer, P. M. Winkler, A. Virtanen, N. M. Donahue, K. S. Carslaw, U. Baltensperger, I. Riipinen, J. Curtius, D. R. Worsnop and M. Kulmala, Nat. Commun., 2016, 7, 11594.

48 J. Lengyel, J. Kočišek, V. Poterya, A. Pysanenko, P. Svrčková, M. Fárnk, D. K. Zaouris and J. Fedor, J. Chem. Phys., 2012, 137, 034304.

49 J. J. Potoff and J. I. Siepmann, AIChE J., 2001, 47, 1676-1682. 50 R. D. Levine and R. B. Bernstein, Molecular reaction dynamics and chemical reactivity, Oxford University Press, 1987.

51 M. G. Martin and J. I. Siepmann, J. Phys. Chem. B, 1998, 102, 2569-2577.

52 S. Tsuzuki, T. Uchimaru, M. Mikami and K. Tanabe, J. Phys. Chem. A, 2002, 106, 3867-3872.

53 P. H. McMurry, J. Colloid Interface Sci., 1980, 78, 513-527.

54 R. Wegscheider, Monatsh. Chem., 1901, 32, 849-906.

55 L. Onsager, Phys. Rev., 1931, 37, 405.

56 J. E. McDonald, Am. J. Phys., 1962, 30, 870-877.

57 S. L. Girshick and C. Chiu, J. Chem. Phys., 1990, 93, 1273-1277.

58 J. Merikanto, E. Zapadinsky, A. Lauri and H. Vehkamäki, Phys. Rev. Lett., 2007, 98, 145702.

59 M. J. McGrath, T. Olenius, I. K. Ortega, V. Loukonen, P. Paasonen, T. Kurtén, M. Kulmala and H. Vehkamäki, Atmos. Chem. Phys., 2012, 12, 2345-2355.

60 J. L. Katz and H. Wiedersich, J. Colloid Interface Sci., 1977, 61, 351-355.

61 M. J. Frisch, G. W. Trucks, H. B. Schlegel, G. E. Scuseria, M. A. Robb, J. R. Cheeseman, G. Scalmani, V. Barone, G. A. Petersson, H. Nakatsuji, X. Li, M. Caricato, A. Marenich, J. Bloino, B. G. Janesko, R. Gomperts, B. Mennucci, H. P. Hratchian, J. V. Ortiz, A. F. Izmaylov, J. L. Sonnenberg, D. Williams-Young, F. Ding, F. Lipparini, F. Egidi, J. Goings, B. Peng, A. Petrone, T. Henderson, D. Ranasinghe, V. G. Zakrzewski, J. Gao, N. Rega, G. Zheng, W. Liang, M. Hada, 
M. Ehara, K. Toyota, R. Fukuda, J. Hasegawa, M. Ishida, T. Nakajima, Y. Honda, O. Kitao, H. Nakai, T. Vreven, K. Throssell, J. A. Montgomery, J. E. Peralta, F. Ogliaro, M. Bearpark, J. J. Heyd, E. Brothers, K. N. Kudin, V. N. Staroverov, T. Keith, R. Kobayashi, J. Normand, K. Raghavachari, A. Rendell, J. C. Burant, S. S. Iyengar, J. Tomasi, M. Cossi, J. M. Millam, M. Klene, C. Adamo, R. Cammi, J. W. Ochterski, R. L. Martin, K. Morokuma, O. Farkas, J. B. Foresman and D. J. Fox, Gaussian09, Revision A.1, 2016.

62 Y. Zhao and D. G. Truhlar, Theor. Chem. Acc., 2008, 120, 215-241.

63 R. A. Kendall, T. H. Dunning and R. J. Harrison, J. Chem. Phys., 1992, 96, 6796-6806.

64 NIST Computational Chemistry Comparison and Benchmark Database, ed. R. D. J. Nist III, 2019.

65 K. H. Lemke and T. M. Seward, Chem. Phys. Lett., 2013, 573, 19-23.

66 X. Xie, C. Wu, Y. Liu, W. Huang, Y. Deng, Y. Liu, Q. Gong and C. Wu, Phys. Rev. A: At., Mol., Opt. Phys., 2014, 90, 033411.

67 P. H. McMurry and C. Li, Aerosol Sci. Technol., 2017, 51, 1057-1070.

68 Y. Negishi, T. Nagata and T. Tsukuda, Chem. Phys. Lett., 2002, 364, 127-132.

69 O. Ingolfsson and A. M. Wodtke, J. Chem. Phys., 2002, 117, 3721-3732.
70 U. Näher, U. Zimmermann and T. P. Martin, J. Chem. Phys., 1993, 99, 2256-2260.

71 J. Bourgalais, V. Roussel, M. Capron, A. Benidar, A. W. Jasper, S. J. Klippenstein, L. Biennier and S. D. Le Picard, Phys. Rev. Lett., 2016, 116, 113401.

72 K. M. Duff, PhD thesis, Massachusetts Institute of Technology, 1964.

73 C. Lettieri, D. Paxson, Z. Spakovszky and P. BryanstonCross, J. Eng. Gas Turbines Power, 2018, 140, 041701.

74 J. Wedekind, A.-P. Hyvärinen, D. Brus and D. Reguera, Phys. Rev. Lett., 2008, 101, 125703.

75 D. Brus, V. Ždmal and F. Stratmann, J. Chem. Phys., 2006, 124, 164306.

76 D. Brus, A.-P. Hyvärinen, J. Wedekind, Y. Viisanen, M. Kulmala, V. Ždmal, J. Smolk and H. Lihavainen, J. Chem. Phys., 2008, 128, 134312.

77 M. A. L. J. Fransen, J. Hrubý, D. M. J. Smeulders and M. E. H. van Dongen, J. Chem. Phys., 2015, 142, 164307.

78 D. Kashchiev, J. Chem. Phys., 1996, 104, 8671-8677.

79 B. E. Wyslouzil, G. Wilemski, M. G. Beals and M. B. Frish, Phys. Fluids, 1994, 6, 2845-2854.

80 D. Barschdorff, Phys. Fluids, 1975, 18, 529-535.

81 L. R. Dumitrescu, H. Huinink, D. M. J. Smeulders, J. A. M. Dam and S. V. Gaastra-Nedea, J. Chem. Phys., 2018, 148, 194502.

82 R. H. Heist, J. Ahmed and M. Janjua, J. Phys. Chem., 1995, 99, 375-383. 